\title{
Anemia and blood transfusion in the critically ill patient with cardiovascular disease
}

\author{
Annemarie B. Docherty ${ }^{1,2^{*}}$ and Timothy S. Walsh ${ }^{1,2}$
}

\begin{abstract}
This article is one of ten reviews selected from the Annual Update in Intensive Care and Emergency Medicine 2017. Other selected articles can be found online at http://ccforum.com/series/ annualupdate2017. Further information about the Annual Update in Intensive Care and Emergency Medicine is available from http://www.springer. com/series/8901.
\end{abstract}

\section{Background}

\section{Anemia and cardiovascular disease}

Approximately seven million people in the United Kingdom, and $30 \%$ of patients admitted to the ICU have co-existing cardiovascular disease (CVD) [1-3] and this proportion may rise as the average age of both the general population and patients admitted to the ICU increase. Patients with CVD will have impaired compensatory mechanisms to enable maximum oxygen delivery to the tissues in the event of anemia (Fig. 1). Anemia causes an increase in cardiac output, which stresses the heart to increase heart rate and stroke volume. In acute illness, global oxygen demand is increased, further stressing the heart. This is exacerbated by the frequent presence of tachycardia and hypotension, which reduce blood flow to the coronary arteries, and by catecholamines that increase myocardial work. Significant left ventricular coronary flow occurs only during diastole and the subendocardial region is particularly at risk of ischemia because of the high pressure in the left ventricle [4]. At rest, the myocardium extracts approximately $75 \%$ of the oxygen

\footnotetext{
* Correspondence: annemarie.docherty@ed.ac.uk

'Department of Anaesthesia, Critical Care, Pain Medicine, and Intensive Care Medicine, University of Edinburgh, Edinburgh, UK

${ }^{2}$ University of Edinburgh, Centre for Inflammation Research, Edinburgh, UK
}

delivered by coronary blood flow [5], and there is therefore little reserve when myocardial oxygen consumption is increased in critical illness. Atheroma-related flow limitation further compromises myocardial oxygen delivery.

\section{Anemia and outcomes in patients with cardiovascular disease}

Anemia is associated with worse outcomes in patients with CVD, both in terms of severity of illness, and mortality. Anemia is a significant risk factor in ischemic heart disease (IHD), correlating with advanced IHD, chronic heart failure, rhythm disturbance and higher mortality rate in comparison to non-anemic patients [6]. Anemia is also an independent predictor of major adverse cardiovascular events in patients across the spectrum of acute coronary syndrome (ACS) [7]. Anemia in heart failure is associated with impaired functional capacity and cardiac function, renal dysfunction, increased rate of hospitalizations and poor prognosis [8]. However, these studies are all observational, and the direction of causality is difficult to ascertain - anemia may cause the worse outcomes, or it may be a reflection of the severity of the underlying chronic disease. It therefore follows that correction with red blood cells (RBCs) may not improve patient prognosis.

\section{Evidence from transfusion trials}

All major RBC transfusion trials have compared restrictive with liberal transfusion strategies based on higher versus lower hemoglobin thresholds for transfusion [9-13]. Trials based in the ICU have shown that a more restrictive transfusion threshold of $7.0 \mathrm{~g} / \mathrm{dl}$ is as safe as a more liberal threshold for the general ICU population $[9,11,14]$. A recent systematic review did not find any association with mortality, overall morbidity or myocardial infarction when comparing restrictive transfusion strategies with liberal transfusion strategies; 


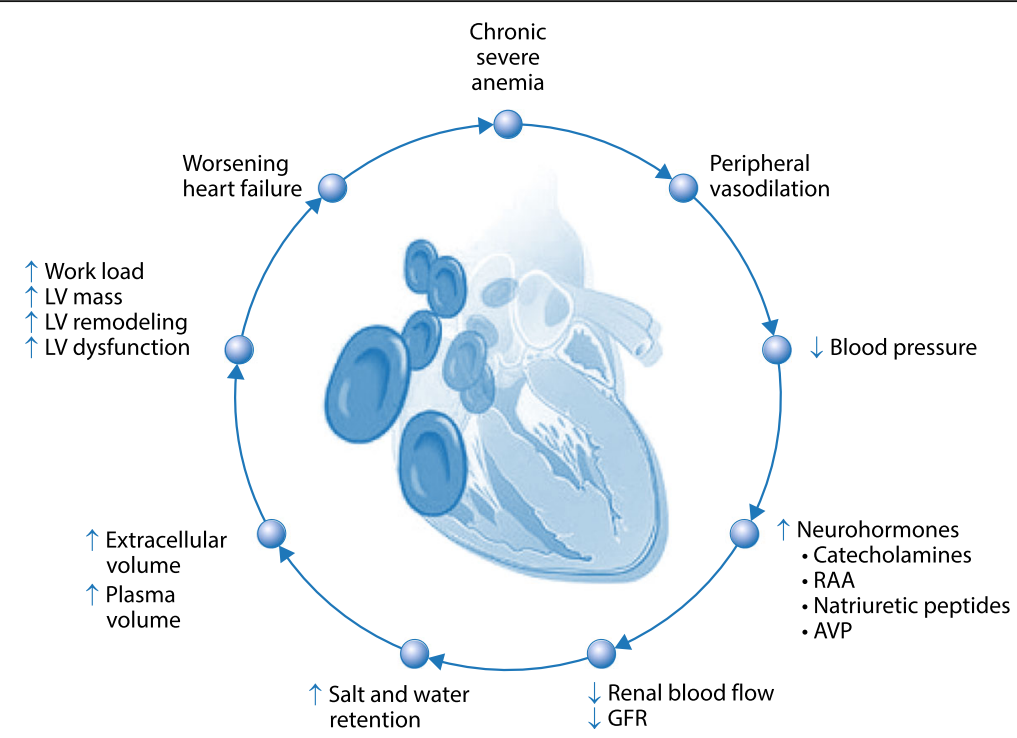

Fig. 1 The impact of chronic severe anemia on myocardial function. LV: left ventricular; AVP: arginine vasopressin; RAA: renin-angiotensin-aldosterone; GFR: glomerular filtration rate. Reproduced from [50] with permission

however, the overall quality of evidence was low [15]. A Cochrane review indicated that restrictive transfusion strategies were not associated with an increased rate of adverse events (mortality, cardiac events, stroke, pneumonia and thromboembolism) compared with liberal transfusion strategies. Restrictive transfusion strategies were associated with a reduction in hospital mortality but not in 30-day mortality [16]. A review published in 2014 using restrictive hemoglobin transfusion triggers of $7 \mathrm{~g} / \mathrm{dl}$ showed reductions in in-hospital mortality, total mortality, rebleeding, ACS, pulmonary edema, and bacterial infections compared with liberal transfusion [17].

However, these trials were based in general ICU cohorts, and there is the risk of practice misalignment, whereby inclusion of heterogeneous populations in trials can mask potentially divergent effects in subpopulations [18]. Both of the major transfusion trials in ICUs had underpowered pre-defined subgroups that suggested that a more liberal transfusion threshold may be beneficial in patients with CVD $[9,11]$. Evidence is also limited by the under-representation of patients with CVD in trials. Observational studies suggest the prevalence of CVD in ICU patients is around $30 \%$ [1, 3]; however patients with CVD accounted for only $20 \%$ of patients recruited to the Transfusion Requirements in Critical Care (TRICC) trial compared with $29 \%$ of patients excluded [9], and only $14 \%$ of patients recruited to the Transfusion Requirements in Septic Shock (TRISS) trial [11]. A trial undertaken in patients presenting with acute gastrointestinal bleeding trial excluded all patients with significant CVD [12].

\section{Evidence in patients with co-existing cardiovascular disease}

There have been few trials aimed specifically at transfusion thresholds in critically ill patients with co-existing CVD. Two recent systematic reviews in cardiac surgery [19] and in perioperative transfusion practice (including cardiac surgery) [20] reported higher mortality with a restrictive transfusion threshold. Our systematic review [21] found only 11 blood transfusion threshold randomized controlled trials (RCTs) that included patients with co-existing CVD, either as the whole population $[10,22-24]$, as a pre-defined subgroup $[9,11,25]$ or as a high proportion of patients [14, 26-28]. We found no evidence of a difference in 30-day mortality between restrictive and liberal transfusion thresholds. However, we found an increased risk of new ACS in patients with co-existing CVD who were randomized to a restrictive blood transfusion threshold (Figs. 2 and 3). The restrictive transfusion threshold for most of the included trials was $8 \mathrm{~g} / \mathrm{dl}$ compared with a liberal transfusion threshold of $10 \mathrm{~g} / \mathrm{dl}$. These trials do not, therefore, provide high quality evidence that the widely recommended 'default' transfusion trigger of $7 \mathrm{~g} / \mathrm{dl}$ is as safe as higher thresholds for preventing ACS in patients with CVD. There was no difference in the incidence of pulmonary edema between restrictive and liberal thresholds; however pulmonary edema can result from both transfusion-related circulatory overload and ACS, and these were not reported separately in the different trials.

Current guidelines reflect the paucity of evidence in patients with co-existing cardiovascular disease (Table 1). 


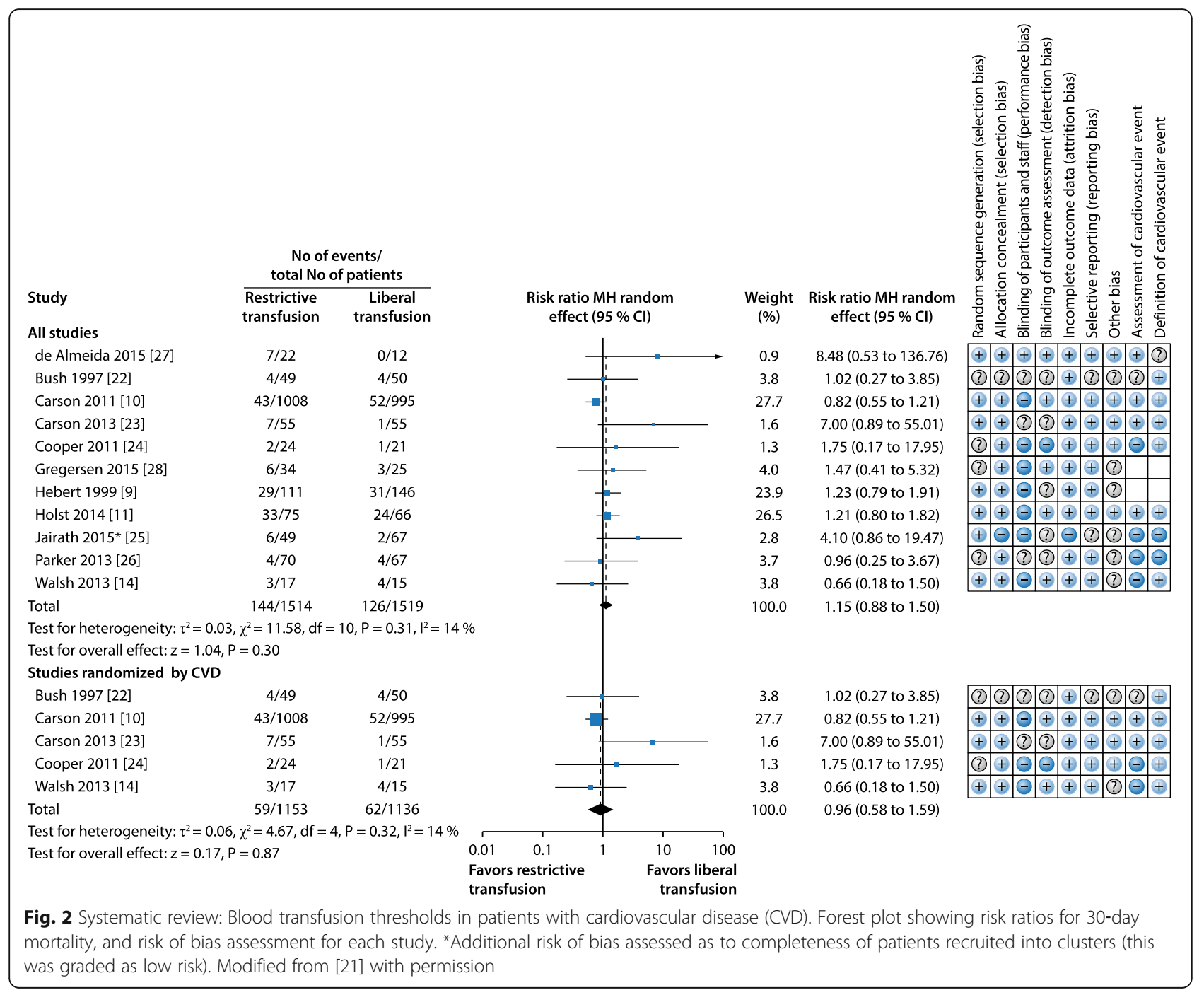

\section{Clinician variability in decision making}

Audits of blood transfusion practice in the UK have consistently shown that around $20 \%$ of blood product usage is outside guideline recommendations [29]. This variation in practice was evident in an analysis of the ABLE trial (Age of transfused blood in critically ill adults), which found that the presence of co-existing CVD modified transfusion thresholds [30].

\section{Future trial design}

A pragmatic RCT of restrictive versus liberal blood transfusion thresholds in patients with CVD with mortality as a primary outcome is likely to encounter the same difficulties as previous trials. In order to find a 5\% reduction in mortality ( 32 to $27 \%, 90 \%$ power), a twoarm trial would require nearly 2,000 patients. Within this population will be patients with differing severity of cardiovascular disease, and differing severity of acute illness, and there is again the risk of practice misalignment. Using the 'PICO' model, we address some of the difficulties a future trial might encounter and offer some potential solutions.

\section{Population}

Critically ill patients with co-existing CVD are not all the same. There is a spectrum of severity of both CVD and critical illness, and it follows that the balance of risks and benefits of transfusion may change along this spectrum.

One approach could be to limit the trial population to the highest risk group, such as those with high severity of illness scores at presentation to the ICU (e. g., APACHE II score $>19$ ), or those with known coronary artery disease. This would mean that we are focusing on the group in which we are most likely to see a difference in outcome between restrictive and liberal thresholds. In addition to this, these patients have high hospital and longer-term mortality, which may make trial numbers 


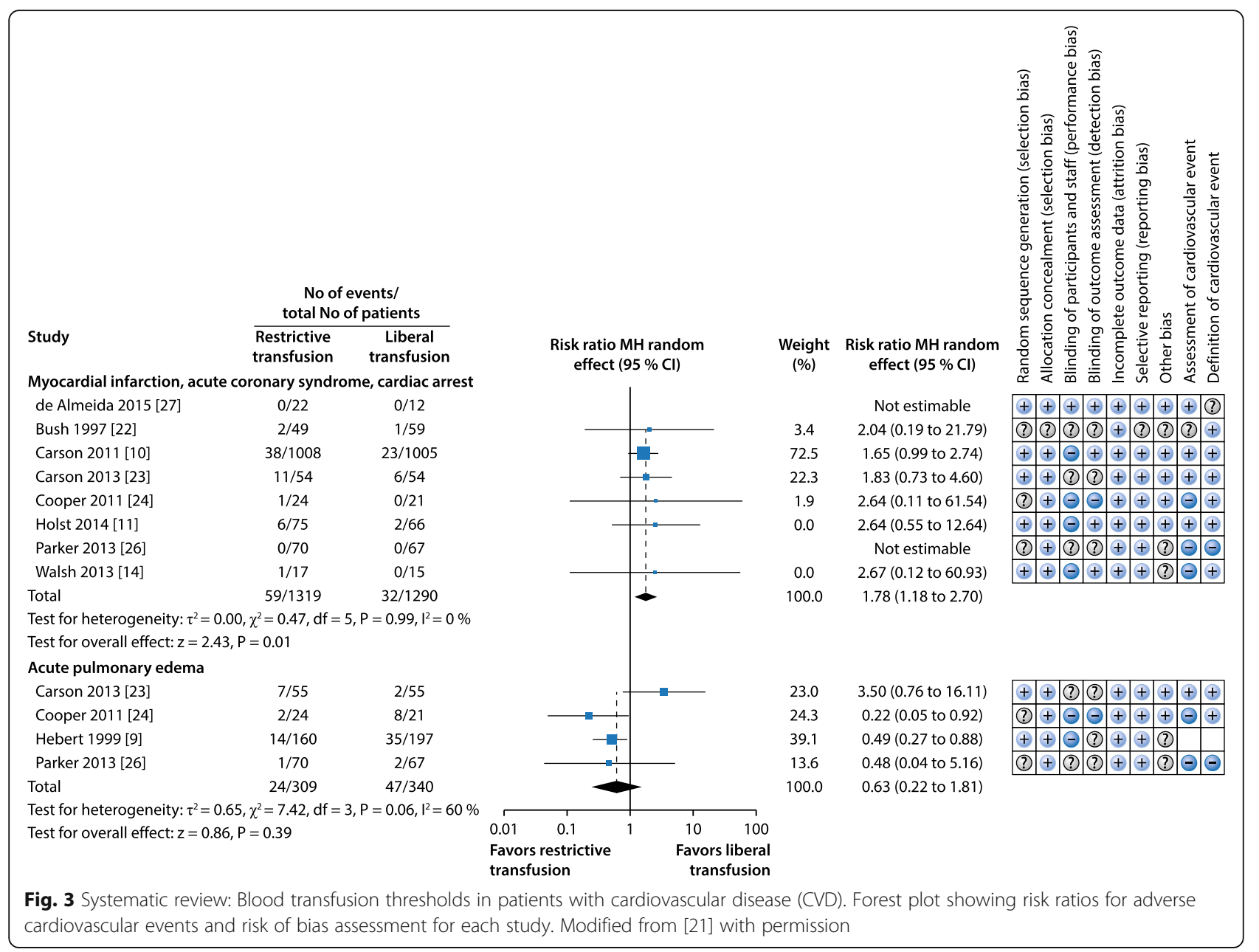

more manageable. If no difference is found, then we could say with confidence that patients with CVD do not benefit from higher transfusion thresholds. However, if there is a benefit in this high-risk group (and from previous trials, we have seen no benefit in patients without CVD), we would be unable to recommend practice for the low-risk CVD group - patients who are either less critically ill or have milder co-existing CVD. A subsequent trial would potentially need to be undertaken in this group.
It is physiologically appealing to design a trial that individualizes transfusion based on patient risk of mortality or ACS. Those patients at high risk would be transfused at a higher threshold than those at lower risk. Significant work would need to be carried out modelling risk in this population to inform the trial design, and observational studies are ongoing [31]. An adaptive trial design, allowing the risk algorithm to be informed by previous participants in the trial would reduce the risk to patients of being

Table 1 Table of guidelines for red blood cell transfusion in patients with cardiovascular disease

\begin{tabular}{llll}
\hline Organization & Year & $\begin{array}{l}\text { Recommendation } \\
\text { for general }\end{array}$ & Recommendation for CVD \\
\hline $\begin{array}{l}\text { British Committee for Standards } \\
\text { in Haematology [38] }\end{array}$ & 2013 & $\begin{array}{l}7.0 \mathrm{~g} / \mathrm{dl} \text {, target } \\
7.0-9.0 \mathrm{~g} / \mathrm{dl}\end{array}$ & Stable angina should have a Hb maintained > 7.0 g/dl \\
$\begin{array}{l}\text { NICE: National Institute for Health } \\
\text { and Clinical Excellence [51] }\end{array}$ & 2015 & $\begin{array}{l}7.0 \mathrm{~g} / \mathrm{dl} \text {, target } \\
7.0-9.0 \mathrm{~g} / \mathrm{dl}\end{array}$ & $\begin{array}{l}\text { ACS: transfusion threshold of } 8.0 \mathrm{~g} / \mathrm{dl} \text {, target of 8.0-10.0 g/dl } \\
\text { Chronic: further research }\end{array}$ \\
$\begin{array}{l}\text { Association of Anaesthetists of Great Britain } \\
\text { and Ireland [52] }\end{array}$ & 2016 & $7.0 \mathrm{~g} / \mathrm{dl}$ & $\begin{array}{l}\text { Uncertainty remains for patients with ischemic heart disease, } \\
\text { American Association of Blood Banks (AABB) [53] }\end{array}$ \\
higher thresholds (8.0 g/dl) may be appropriate
\end{tabular}

ACS acute coronary syndrome, CVD cardiovascular disease, $\mathrm{Hb}$ hemoglobin 
randomized to a harmful threshold and would be more cost-effective.

\section{Intervention}

$\mathrm{RBC}$ transfusion is current standard practice for correcting anemia in critically ill patients, and it would be logical to continue this in a future trial. Iron therapy plus or minus erythropoietin would be another potential intervention. There is a functional iron deficiency in critical illness and a theoretical increased risk of bacterial infection with the use of iron, and although there is an ongoing trial into intravenous iron in critical illness [32], use of iron or erythropoietin is not standard during the acute phase of critical illness. Previous large trials of erythropoietin have not shown efficacy for significantly reducing $\mathrm{RBC}$ transfusions and/or increasing hemoglobin by clinically relevant amounts [33]. A limitation of both iron and erythropoietin is their slow impact on erythropoiesis and hemoglobin level in the context of acute illness. It seems likely that RBC transfusion will remain the therapy of choice for acutely increasing hemoglobin concentration in critical illness.

\section{Comparator}

Previous transfusion trials have all compared liberal with restrictive transfusion hemoglobin thresholds. There are limitations in using hemoglobin, given that the concentration is significantly affected by fluid resuscitation, however this is a pragmatic approach which is reproducible and routinely measured. In a population in which patients are not sedated and ventilated, an alternative could be to transfuse based on symptomatology, or potentially anaerobic threshold, but this is unlikely to be feasible in the ICU.

Thresholds have varied between trials (restrictive 7.0$9.7 \mathrm{~g} / \mathrm{dl}$, liberal $9.0-11.3 \mathrm{~g} / \mathrm{dl}$ [21]), with overlap between restrictive thresholds in some trials and liberal in others. The larger the difference in thresholds, the more likely a difference will be shown, and a trial of $7 \mathrm{~g} / \mathrm{dl}$ (current practice excepting ACS) vs $90 \mathrm{~g} / \mathrm{l}$ would need fewer patients than $7.5-8.0 \mathrm{~g} / \mathrm{dl}$ vs $9.0 \mathrm{~g} / \mathrm{dl}$. Clinicians need equipoise, and if clinicians are unwilling to randomize patients with CVD to a low threshold of $7.0 \mathrm{~g} / \mathrm{dl}$ then a higher threshold must be agreed on, otherwise high-risk patients may be excluded from the trial.

\section{Outcomes}

\section{Mortality}

The majority of blood transfusion threshold trials have used 30-day mortality as their primary outcome. There are many causes of mortality in critically ill patients and it is difficult to argue that mortality during the first few days of critical illness is anything other than a result of the severity of presenting illness. A $10-20 \%$ difference in hemoglobin concentration seems to lack biological plausibility to alter this substantially. Longer-term mortality may be a more appropriate endpoint either in isolation or combination with measures of quality of life.

\section{Acute coronary syndrome}

ACS is an appropriate outcome for blood transfusion trials, particularly in patients with co-existing CVD. However, diagnosis of ACS in critically ill patients is not straightforward. Standard diagnosis comprises patient symptoms and signs, evidence of ischemia on the electrocardiogram (EKG), and a rise and fall pattern of cardiac biomarker (usually troponin I or troponin T) [34]. Standard symptoms are often masked by sedation, delirium or analgesia. EKGs are not performed routinely and there is significant interobserver variability [35]. Troponin release is prevalent in the critically ill $[1,36]$ and there are multiple causes. Potential cardiac mechanisms include increased thrombogenicity leading to coronary plaque rupture and thrombosis (type I myocardial infarction) or underlying critical coronary artery disease leading to an oxygen supply/demand imbalance (type II myocardial infarction) [34]. However, elevated troponin is also recognized in sepsis, end-stage renal disease, acute exacerbations of chronic obstructive pulmonary disease (COPD) and acute intracerebral pathology [37]. This finding may be as a result of underlying cardiac disease, but there is also evidence of troponin release as a result of direct toxicity from cytokines, stretch-mediated troponin release, or ongoing subclinical myocardial injury due to uremia and impaired excretion [37]. Our systematic review found that cardiovascular events were diagnosed by unblinded clinicians in a third of trials, and that the criteria for the diagnosis of myocardial infarction were inconsistent (Table 2), and this resulted in a low GRADE quality of evidence [21]. The diagnosis of ACS in high-risk patients who are unable to communicate their symptoms, have non-specific EKG changes, and multiple causes for troponin elevation is challenging and often arbitrary. Before we are able to use ACS as an objective endpoint, we need to be able to diagnose its presence or absence with accuracy and precision.

\section{Duration of mechanical ventilation}

Weaning consists of liberation from mechanical ventilation and extubation. Patients with CVD may develop myocardial ischemia associated with the increased sympathetic activation associated with difficulty weaning from the ventilator. Studies have suggested an association between anemia and failure to wean, and between $\mathrm{RBC}$ transfusion and reduction in the work of breathing [38]; however this is not a consistent finding. Transfusion in anemic patients with CVD prior to weaning could potentially reduce the incidence of ACS, as well as 
Table 2 Acute coronary syndrome (ACS) in patients with co-existing cardiovascular disease in critical care blood transfusion threshold trials. Diagnosis made by Investigator (I) or Clinician (C)

\begin{tabular}{|c|c|c|c|c|}
\hline Author, year & Population & Blinded $y / n$ & Diagnosis of ACS & $\begin{array}{l}\text { Incidence of } \\
\text { new ACS }\end{array}$ \\
\hline de Almeida, 2015 [27] & Major abdominal cancer surgery & Y (I) & $\begin{array}{l}\text { Clinical symptoms suggesting myocardial ischemia } \\
\text { with } \geq 1 \text { of the following: } \\
\text { increase/decrease in cTnl ( } \geq 1 \text { value }>99^{\text {th }} \\
\text { centile upper reference limit); } \\
\text { EKG changes: new Q waves, ST elevation, new LBBB; } \\
\text { Image-based evidence of new loss of viable myocardium }\end{array}$ & $\begin{array}{l}\text { R: } 0 / 22 \\
\text { L: } 0 / 12\end{array}$ \\
\hline Hebert, 1999 [9] & General ICU & $?(1)$ & Unclear & * \\
\hline Holst, 2014 [11] & Septic shock & $Y(I)$ & $\begin{array}{l}\text { Symptoms, EKG signs, or elevated biomarker levels } \\
\text { resulting in an intervention }\end{array}$ & $\begin{array}{l}\text { R: 6/75 } \\
\text { L: } 2 / 66\end{array}$ \\
\hline Walsh, 2013 [14] & Older, mechanically ventilated & $N(C)$ & Troponin rise, new EKG change & $\begin{array}{l}\text { R: } 1 / 17 \\
\text { L: } 0 / 15\end{array}$ \\
\hline
\end{tabular}

*All complications, including shock, myocardial infarction, unstable angina and cardiac arrest, with the exception of acute pulmonary edema ( 9 vs. $18 \%$; $p<0.01)$, were comparable in both groups $(p>0.05)$. $L B B B$ left bundle branch block, $R$ restrictive, $L$ liberal, $T n$ troponin, EKG electrocardiogram

being both clinically effective and cost-effective. No published ICU trials have commented on duration of mechanical ventilation specifically for patients with CVD. Data regarding ICU and hospital length of stay are also scarce (Table 3).

\section{Health-related quality of life (HRQOL)}

There are few data regarding the prevalence and time course of anemia after intensive care. One study showed that $77 \%$ of patients were still anemic at hospital discharge and that nearly half the patients who were in the ICU for seven or more days had hemoglobin concentrations $<10.0 \mathrm{~g} / \mathrm{dl}$ [39]. In a study looking at patients mechanically ventilated $>24 \mathrm{~h}$ and discharged from ICU with hemoglobin concentrations $<10.0 \mathrm{~g} / \mathrm{dl}$, half the patients were still anemic at six months [40]. The anemia was predominantly normochromic and normocytic, consistent with ongoing inflammation, inappropriate erythropoietin response and poor marrow $\mathrm{RBC}$ production, although the contribution of iron deficiency is difficult to ascertain in these states. These patients had a reduced mean SF-36 score at both 3 and 6 months compared to the normal population. Studies looking at HRQOL for anemia and other chronic disease such as malignancy [41] and end-stage renal disease [42] consistently show an association between hemoglobin concentrations and HRQOL. Fatigue is a prevalent symptom

Table 3 Duration of mechanical ventilation, length of stay in ICU/hospital (LOS) in patients with co-existing cardiovascular disease in critical care blood transfusion threshold trials

\begin{tabular}{llll}
\hline Author, year & Population & ICU LOS & $\begin{array}{l}\text { Hospital } \\
\text { LOS }\end{array}$ \\
\hline Hebert, 1999 [9] & General ICU & R: $9.3(9.7)$ & R: $28.8(19.5)$ \\
& & L: $10.4(10.3)$ & L: $30.6(18.8)$ \\
Walsh, 2013 [14] & $\begin{array}{l}\text { Older, mechanically } \\
\text { ventilated }\end{array}$ & R: $36.5(26.7)$ & R: $25.6(18.1)$ \\
& L: $53.3(40.1)$ & L: $36.3(28.3)$
\end{tabular}

$R$ restrictive, $L$ liberal among survivors, and many of the physical features of the post-ICU syndrome are typical of anemia [43]. However, the causal association between anemia and fatigue, and reduced HRQOL, in this patient group are not well studied. Equally, there are no high quality studies exploring whether interventions to treat and correct anemia, whether with RBC transfusion or non-transfusion interventions such as iron or erythropoietin, can modify these important outcomes.

\section{Cost-effectiveness}

The cost of a unit of blood is around $£ 120$ in the UK, but this does not take into account the complications avoided and complications arising from transfusion. Evaluation of the cost-effectiveness of RBC transfusion is essential. The combination of very high hospital costs for critically ill survivors [44] and low HRQOL during the months following survivorship means that the loss of quality-adjusted life years (QALYs) is substantial following critical illness. The rationale for blood transfusion is to decrease both deaths and complications, such as new ACS, which might impact further on quality of life, thus improving HRQOL and cost-effectiveness. Few completed ICU studies have included health economic evaluations. Cost-effectiveness analysis of the Transfusion Indication Threshold Reduction (TITRe) II blood transfusion threshold in cardiac surgery trial found no clear difference between restrictive and liberal arms up to three months after surgery [45]. Hemoglobin concentration remained different at hospital discharge in the Restrictive and Liberal Transfusion Strategies in Intensive Care (RELIEVE) trial [14], suggesting that longer term exposure to anemia and its effect on HRQOL is potentially important for survivors. It seems logical for future transfusion trials during critical illness to include an economic evaluation in addition to measuring clinical outcomes, especially in exploring the hypothesis that 
treating anemia might improve quality of life among survivors.

\section{Future areas for research Imaging}

The mechanism of troponin release in critically ill patients with cardiovascular disease is not yet fully understood and the relative contribution of ischemic versus inflammatory injury is unknown. This has potentially important therapeutic implications. At present, imaging is mainly limited to bedside transthoracic echocardiography (TTE) due to concerns regarding transferring unstable patients to isolated locations such as the computed tomography (CT) scanner or for angiography. Standard TTE is technically more difficult in these patients, and has only moderate diagnostic accuracy.

\section{Strain echocardiography}

Strain TTE, is a relatively novel imaging technique and describes the lengthening, shortening or thickening, also known as regional deformation, of the myocardium [46]. It uses the unique 'speckle' pattern visible in the myocardium on routine echo images. It follows the movement of blocks of speckle pattern over time frames and is able to capture longitudinal, circumferential and radial strain (rate of deformation). This algorithm results in objective analyses of myocardial function, and is more sensitive than standard TTE evaluation of left ventricular function. It has been successfully used to demonstrate left ventricular dysfunction in septic patients in critical care [47], and stress cardiomyopathy in patients with subarachnoid hemorrhage [48].

\section{Cardiac magnetic resonance}

Cardiac magnetic resonance is another non-invasive imaging technique that allows for accurate visualization of tissue changes in patients with acute myocardial disease. In the context of troponin elevation in critical illness, it is of particular value in distinguishing myocardial infarction from other myocardial abnormalities such as myocarditis, due to the ability to distinguish between subendocardial and other patterns of fibrosis. Cardiac magnetic resonance is able to detect the increased tissue edema in acute myocardial infarction that lasts up to five weeks and the scar from myocardial necrosis [49]. This means that patients would be able to be scanned in the recovery period for troponin elevations that occurred in acute critical illness.

\section{Blood transfusion in recovery from critical illness}

Given the long trajectory of anemia in critical care survivors, another important area to study is the impact of blood transfusion in patients once they have recovered from their critical illness. It would be possible to look at both physiological parameters and patient HRQOL before and after RBC transfusion. Continuous pulmonary exercise testing (C-PEX) can give an objective assessment of anaerobic threshold, as well as monitor for ischemia by EKG monitoring. Important patient outcomes, such as fatigue and breathlessness, can be explored with qualitative patient interviews or more structured questionnaires.

\section{Conclusion}

There is biological plausibility that patients with CVD may benefit from higher transfusion thresholds than patients without CVD. Evidence from a systematic review and meta-analysis in this population suggest that there is no difference in 30-day mortality, but there is an increased risk of ACS in patients with CVD who were randomized to a restrictive transfusion threshold compared with a more liberal threshold. We suggest that a more liberal transfusion threshold $(>80 \mathrm{~g} / \mathrm{l})$ in this population should be used until a high-quality trial including endpoints for longer term mortality, ACS, quality of life and cost effectiveness has been performed.

\section{Acknowledgements \\ Not applicable. \\ Funding \\ Publication costs were funded by the University of Ediburgh.}

Availability of data and materials

Not applicable.

Authors' contributions

ABD and TSW conceived, drafted and revised the manuscript. Both authors read and approved the final manuscript.

\section{Competing interests}

The authors declare that they have no competing interests.

Consent for publication

Not applicable.

Ethics approval and consent to participate

Not applicable.

Published online: 21 March 2017

References

1. Ostermann M, Lo J, Toolan M, et al. A prospective study of the impact of serial troponin measurements on the diagnosis of myocardial infarction and hospital and six-month mortality in patients admitted to ICU with noncardiac diagnoses. Crit Care. 2014;18:R62.

2. British Heart Foundation (2015) Cardiovascular Disease Statistics 2015. https://www.bhf.org.uk/publications/statistics/cvd-stats-2015. Accessed September 2016

3. Walsh TS, McClelland DB, Lee RJ, et al. Prevalence of ischaemic heart disease at admission to intensive care and its influence on red cell transfusion thresholds: multicentre Scottish Study. Br J Anaesth. 2005;94: 445-52.

4. Walsh TS, McClelland DB. When should we transfuse critically ill and perioperative patients with known coronary artery disease? $\mathrm{Br} J$ Anaesth. 2003;90:719-22.

5. Tune JD, Gorman MW, Feigl EO. Matching coronary blood flow to myocardial oxygen consumption. J Appl Physiol. 2004;97:404-15.

6. Zeidman A, Fradin Z, Blecher A, Oster HS, Avrahami Y, Mittelman M. Anemia as a risk factor for ischemic heart disease. Isr Med Assoc J. 2004;6:16-8. 
7. Sabatine MS, Morrow DA, Giugliano RP, et al. Association of hemoglobin levels with clinical outcomes in acute coronary syndromes. Circulation. 2005;111:2042-9.

8. Ezekowitz JA, McAlister FA, Armstrong PW. Anemia is common in heart failure and is associated with poor outcomes: insights from a cohort of 12 065 patients with new-onset heart failure. Circulation. 2003;107:223-5.

9. Hebert PC, Wells G, Blajchman MA, et al. A multicenter, randomized, controlled clinical trial of transfusion requirements in critical care. Transfusion Requirements in Critical Care Investigators, Canadian Critical Care Trials Group. N Engl J Med. 1999;340:409-17.

10. Carson JL, Terrin ML, Noveck H, et al. Liberal or restrictive transfusion in high-risk patients after hip surgery. N Engl J Med. 2011;365:2453-62.

11. Holst LB, Haase N, Wetterslev J, et al. Lower versus higher hemoglobin threshold for transfusion in septic shock. N Engl J Med. 2014;371:1381-91.

12. Villanueva C, Colomo A, Bosch A, et al. Transfusion strategies for acute upper gastrointestinal bleeding. N Engl J Med. 2013;368:11-21.

13. Murphy GJ, Pike K, Rogers CA, et al. Liberal or restrictive transfusion after cardiac surgery. N Engl J Med. 2015;372:997-1008.

14. Walsh TS, Boyd JA, Watson D, et al. Restrictive versus liberal transfusion strategies for older mechanically ventilated critically ill patients: a randomized pilot trial. Crit Care Med. 2013;41:2354-63.

15. Holst LB, Petersen MW, Haase N, Perner A, Wetterslev J. Restrictive versus liberal transfusion strategy for red blood cell transfusion: systematic review of randomised trials with meta-analysis and trial sequential analysis. BMJ. 2015;350:h1354.

16. Carson JL, Carless PA, Hebert PC. Transfusion thresholds and other strategies for guiding allogeneic red blood cell transfusion. Cochrane Database Syst Rev. 2012;CD002042

17. Salpeter SR, Buckley JS, Chatterjee S. Impact of more restrictive blood transfusion strategies on clinical outcomes: a meta-analysis and systematic review. Am J Med. 2014;127(e123):124-31.

18. Deans KJ, Minneci PC, Suffredini AF, et al. Randomization in clinical trials of titrated therapies: unintended consequences of using fixed treatment protocols. Crit Care Med. 2007:35:1509-16.

19. Patel NN, Avlonitis VS, Jones HE, et al. Indications for red blood cell transfusion in cardiac surgery: a systematic review and meta-analysis. Lancet Haematol. 2015;2:e543-53.

20. Fominskiy E, Putzu A, Monaco F, et al. Liberal transfusion strategy improves survival in perioperative but not in critically ill patients. A meta-analysis of randomised trials. Br J Anaesth. 2015:115:511-9.

21. Docherty $A B, O$ 'Donnell $R$, Brunskill $S$, et al. Effect of restrictive versus liberal transfusion strategies on outcomes in patients with cardiovascular disease in a non-cardiac surgery setting: systematic review and meta-analysis. BMJ. 2016:352:11351.

22. Bush RL, Pevec WC, Holcroft JW. A prospective, randomized trial limiting perioperative red blood cell transfusions in vascular patients. Am J Surg. 1997;174:143-8

23. Carson JL, Brooks MM, Abbott JD, et al. Liberal versus restrictive transfusion thresholds for patients with symptomatic coronary artery disease. Am Heart J. 2013;165:964-71. e961.

24. Cooper HA, Rao SV, Greenberg MD, et al. Conservative versus liberal red cell transfusion in acute myocardial infarction (the CRIT Randomized Pilot Study). Am J Cardiol. 2011;108:1108-11.

25. Jairath $\mathrm{V}$, Kahan BC, Gray A, et al. Restrictive versus liberal blood transfusion for acute upper gastrointestinal bleeding (TRIGGER): a pragmatic, openlabel, cluster randomised feasibility trial. Lancet. 2015;386:137-44.

26. Parker MJ. Randomised trial of blood transfusion versus a restrictive transfusion policy after hip fracture surgery. Injury. 2013:44:1916-8.

27. de Almeida JP, Vincent JL, Galas FR, et al. Transfusion requirements in surgical oncology patients: a prospective, randomized controlled trial. Anesthesiology. 2015;122:29-38.

28. Gregersen M, Damsgaard EM, Borris LC. Blood transfusion and risk of infection in frail elderly after hip fracture surgery: the TRIFE randomized controlled trial. Eur J Orthop Surg Traumatol. 2015;25:1031-8.

29. National Comparative Audit of Blood Transfusion (2011) Audit of Blood in Adult Medical Patients-Part 1. http://hospital.blood.co.uk/media/26862/ncamedical_use_audit_part_1_report.pdf. Accessed September 2016

30. Wilton K, Fowler RA, Walsh T, Lacroix J, Callum J. Variation of red blood cell transfusion thresholds for critically ill patients. Crit Care. 2014;18:106.
31. Docherty AB, Stanworth SJ, Lone NI, Walsh TS (2016) TROPICCAL: TROPonin I in cardiovascular patients in CriticAL care. https://www.ukctg.nihr.ac.uk. Accessed September 2016

32. Litton E, Baker $\mathrm{S}$, Erber W, et al. The IRONMAN trial: a protocol for a multicentre randomised placebo-controlled trial of intravenous iron in intensive care unit patients with anaemia. Crit Care Resusc. 2014;16:285-90.

33. Corwin HL, Gettinger A, Pearl RG, et al. Efficacy of recombinant human erythropoietin in critically ill patients: a randomized controlled trial. JAMA. 2002:288:2827-35

34. Thygesen K, Alpert JS, Jaffe AS, et al. Third universal definition of myocardial infarction. Eur Heart J. 2012:33:2551-67.

35. Mehta S, Granton J, Lapinsky SE, et al. Agreement in electrocardiogram interpretation in patients with septic shock. Crit Care Med. 2011;39:2080-6.

36. Lim W, Qushmaq I, Cook DJ, et al. Elevated troponin and myocardial infarction in the intensive care unit: a prospective study. Crit Care. 2005:9: R636-644.

37. Agewall $\mathrm{S}$, Giannitsis $\mathrm{E}$, Jernberg T, Katus H. Troponin elevation in coronary vs. non-coronary disease. Eur Heart J. 2011;32:404-11.

38. Retter A, Wyncoll D, Pearse R, et al. Guidelines on the management of anaemia and red cell transfusion in adult critically ill patients. Br J Haematol. 2013;160:445-64.

39. Walsh TS, Saleh EE, Lee RJ, McClelland DB. The prevalence and characteristics of anaemia at discharge home after intensive care. Intensive Care Med. 2006:32:1206-13.

40. Bateman AP, McArdle F, Walsh TS. Time course of anemia during six months follow up following intensive care discharge and factors associated with impaired recovery of erythropoiesis. Crit Care Med. 2009;37:1906-12.

41. Sabbatini $P$. The relationship between anemia and quality of life in cancer patients. Oncologist. 2000;5 Suppl 2:19-23.

42. Finkelstein FO, Story K, Firanek C, et al. Health-related quality of life and hemoglobin levels in chronic kidney disease patients. Clin J Am Soc Nephrol. 2009;4:33-8.

43. Walsh TS, Salisbury LG, Merriweather JL, et al. Increased hospital-based physical rehabilitation and information provision after intensive care unit discharge: The RECOVER randomized clinical trial. JAMA Intern Med. 2015; 175:901-10

44. Lone NI, Gillies MA, Haddow C, et al. Five-year mortality and hospital costs associated with surviving intensive care. Am J Respir Crit Care Med. 2016; 194:198-208.

45. Stokes EA, Wordsworth S, Bargo D, et al. Are lower levels of red blood cell transfusion more cost-effective than liberal levels after cardiac surgery? Findings from the TITRe2 randomised controlled trial. BMJ Open. 2016;6, e011311.

46. Gorcsan 3rd J, Tanaka H. Echocardiographic assessment of myocardial strain. J Am Coll Cardiol. 2011;58:1401-13

47. De Geer L, Engvall J, Oscarsson A. Strain echocardiography in septic shock a comparison with systolic and diastolic function parameters, cardiac biomarkers and outcome. Crit Care. 2015:19:122

48. Cinotti R, Piriou N, Launey $Y$, et al. Speckle tracking analysis allows sensitive detection of stress cardiomyopathy in severe aneurysmal subarachnoid hemorrhage patients. Intensive Care Med. 2016;42:173-82.

49. Friedrich MG. Tissue characterization of acute myocardial infarction and myocarditis by cardiac magnetic resonance. JACC Cardiovasc Imaging. 2008; 1:652-62.

50. Anand IS. Anemia and chronic heart failure implications and treatment options. J Am Coll Cardiol. 2008;52:501-11.

51. National Institute for Health and Clinical Excellence (2015) Transfusion. http://www.nice.org.uk/guidance/ng24/evidence/full-guidance-2177160733. Accessed November 2016

52. Klein AA, Arnold P, Bingham RM, et al. AAGBI Guidelines: the use of blood components and their alternatives 2016. Anaesthesia. 2016:71:829-42.

53. Carson JL, Guyatt G, Heddle NM, et al. Clinical Practice Guidelines From the AABB: Red Blood Cell Transfusion Thresholds and Storage. JAMA. 2016;316: $2025-35$ 